\title{
OPTIMIZATION OF STEREOLITHOGRAPHY AND FUSED Deposition Modeling Process Parameters
}

\author{
Ahmet Cekic, Derzija Begic-Hajdarevic, Maida Cohodar, \\ Kenan Muhamedagic \& Maida Osmanlic
}
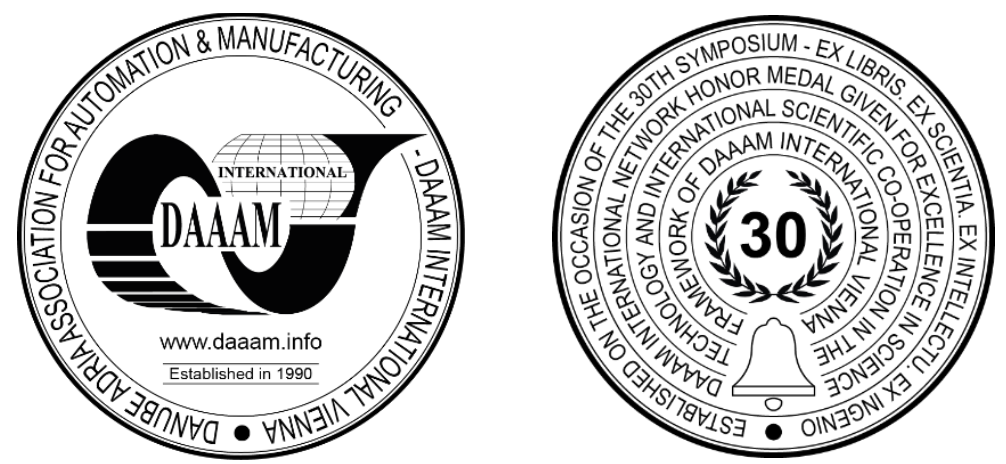

This Publication has to be referred as: Cekic, A[hmet]; Begic-Hajdarevic, D[erzija]; Cohodar, M[aida]; Muhamedagic, K[enan] \& Osmanlic, M[aida] (2019). Optimization of Stereolithography and Fused Deposition Modeling Process Parameters, Proceedings of the 30th DAAAM International Symposium, pp.0681-0687, B. Katalinic (Ed.), Published by DAAAM International, ISBN 978-3-902734-22-8, ISSN 1726-9679, Vienna, Austria

DOI: $10.2507 / 30$ th.daaam.proceedings.093

\begin{abstract}
In this paper was analyzed and experimentally investigated two additive technologies: Stereolithography - SLA i Fused Deposition Modeling - FDM. The dimensional accuracy (deviation from the given dimensions in relation to the previously defined 3D CAD model as well as the surface roughness of the printed samples by the additive technologies FDM and SLA) was analyzed. The process parameters of these additive technologies were optimized in order to achieve better dimensional accuracy and less surface roughness on the products. Additionally, a comparison of FDM and SLA additive technologies was performed.
\end{abstract}

Keywords: reverse engineering; surface roughness; dimensional accuracy; FDM technology, SLA technology.

\section{Introduction}

The application of additive manufacturing technologies are priorities of current research. Additive technologies allow for the rapid and efficient production of very complex physical models, at an early stage in product development. Thus, in the triangle, quality - cost - time, significantly reduce one of the most influential components - product development time, while meeting the other two requirements, a better price and high product quality. The basic principle of most additive technologies is the production of products based on a predefined 3D CAD model by adding material "layer by layer". So the usual classification of additive technologies is done according to the way the layers are built. In this paper, two different additive technologies were analyzed, the technology of fabrication of layers by extrusion and solidification of materials - FDM and technology of fabrication of layers by the process of photoplymerization from a liquid state SLA.

FDM technology builds conceptual models, functional prototypes and end-use parts from various types of thermoplastics, from standard to high performance plastics. However, the disadvantages of the FDM procedure are first of all related to the functionality of the product, which is limited by the choice of material, it is very often necessary to use a supporting structure and therefore to subsequently clean the product. The lines between the layers are visible, the strength of the product is reduced in the direction perpendicular to the direction of build of the product. Temperature 
fluctuations during the process can lead to delamination of the product. In order to reduce the aforementioned deficiencies while increasing the dimensional accuracy and quality of the product surfaces, it is necessary to optimize the process parameters, which is the topic of this paper [1][2][3][4]. There are many parameters that can be adjusted to achieve greater print accuracy: print speed, extrusion rate, nozzle temperature and diameter, layer height, infill density, etc.

Stereolithography processes photopolymers based on acrylic, vinyl or epoxy resins. Products made with stereolithography have high precision, the ability to produce very fine details in many different colors and the smoothest surface finish of all additive technologies. However, the disadvantages of this technology are the following: it requires support structure and post-processing of the product (additional UV solidification), the appearance of internal stresses and deformation of the product during solidification, it requires special space for the device (photopolymers are poisonous in liquid state), there is a limited number of materials that can be used (photopolymers only), etc. The most influential process parameters that affect product quality in addition to product design are the orientation of the product being printed ("top-down" or "bottom-up"), design and location of the supporting structure, layer height and used building materials (standard, engineering, dental, ceramic, etc.) [5][6][7][8].

\section{Experimental procedure}

The aim of the experiments presented in this paper is to investigate the optimal parameters for FDM and SLA technologies, in order to obtain the smallest dimensional deviations of the final product relative to the CAD model and to determine the surface roughness of the product by varying the influencing process parameters. Ultimaker $2+$, Ultimaker 3 , and Ultimaker 5 were used to create the samples using FDM technology. The materials used for the FDM technology are Polylactic Acid - PLA and Polyvinyl acetate - PVA. The wire diameter of both materials is $2.85 \mathrm{~mm}$. Printing samples with SLA tehnology was done on a Formlabs Form 2 device. The materials used to make the product with SLA technology belong to the group of standard or engineering resins, namely: Clear resin, Rigid resin and Tough resin.

In addition to visual inspection, specimen inspection was performed on the following measuring equipment: universal two-coordinate measuring microscope - ZKM 01 - 250C and a Mitutoyo SJ-20 roughness measuring device.

\section{Results and discussions}

\subsection{Effect of printing temperature on the dimensional accuracy of the product}

To test the effect of printing temperature on dimensional accuracy, 10 samples of PLA material were made. The appearance of the sample is shown in Figure 1a. Samples were made on an FDM Ultimaker 2+ device, Figure 1b. The temperature varied between $170{ }^{\circ} \mathrm{C}$ and $260{ }^{\circ} \mathrm{C}$ in $10^{\circ} \mathrm{C}$ increments. An attempt to sample at $170{ }^{\circ} \mathrm{C}$ failed, Figure $1 \mathrm{c}$. The rest of the samples are satisfactory quality and the deviation results are shown in Figure 2.

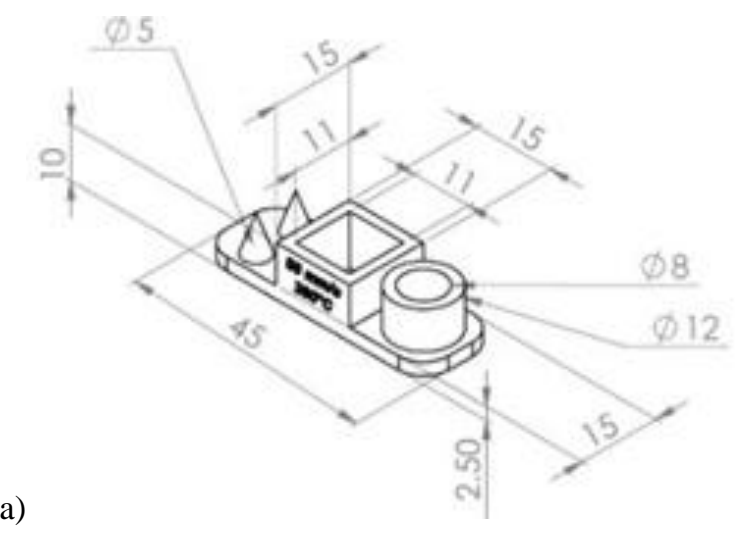

b)

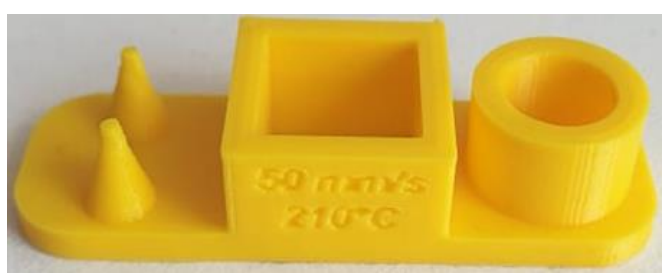

c)

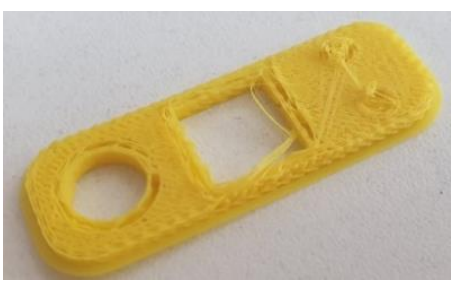

Fig. 1. The sample model obtained in SolidWorks 2019 software, and the appearance of the samples obtained from PLA materials 


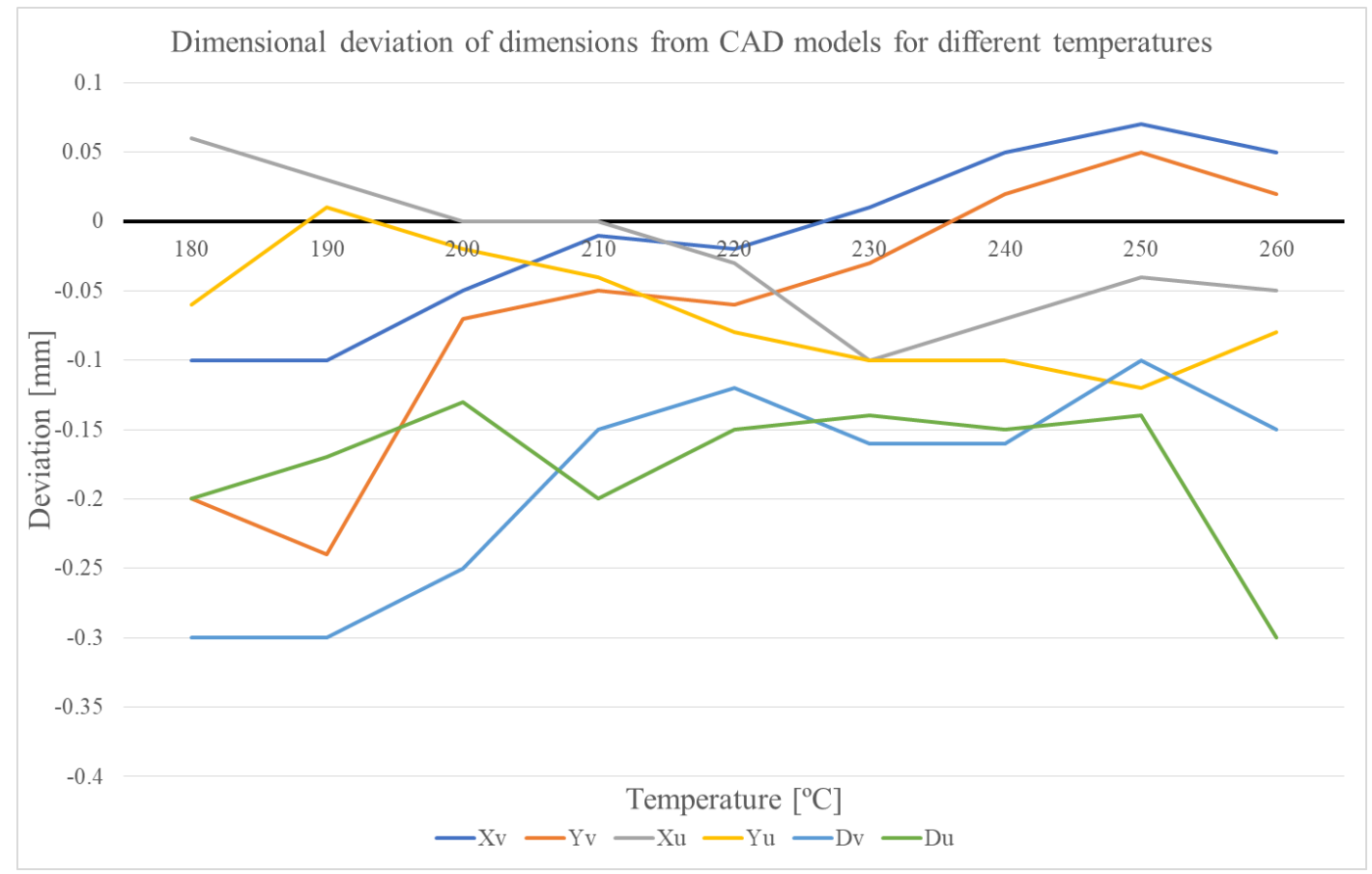

Fig. 2. Dimensional deviation of dimensions from CAD models for different temperatures $\left(\mathrm{X}_{\mathrm{V}}\right.$ - deviation of external measures in the $\mathrm{x}$ axis; $\mathrm{Y}_{\mathrm{V}}$ - deviation of external measures in the $\mathrm{y}$ axis; $\mathrm{Xu}$ - deviation of internal measures in the $\mathrm{x}$ axis; $\mathrm{Yu}$ - deviation of internal measures in the $\mathrm{y}$ axis; Dv - dimensional deviation of the outer diameter of the circle;

$\mathrm{Du}$ - dimensional deviation of the inner diameter of the circle)

By analyzing the deviations of the dimensions shown in Figure 2, it can be concluded that the deviations of the inner dimensions are 3 to 5 times larger than the deviations of the outer dimensions and that they are smallest at temperatures from $210{ }^{\circ} \mathrm{C}$ to $220{ }^{\circ} \mathrm{C}$. Further experimental investigations of the influence of other process parameters on dimension deviations were performed at a print temperature of $210^{\circ} \mathrm{C}$. Printing speed and layer height varied, and this is shown below.

\subsection{Effect of print speed and layer height on dimension accuracy}

The print speed varies from $25 \mathrm{~mm} / \mathrm{s}$ to $125 \mathrm{~mm} / \mathrm{s}$ in $25 \mathrm{~mm} / \mathrm{s}$ increments. The samples were made with three different layer heights: $0.10 \mathrm{~mm}, 0.15 \mathrm{~mm}$ and $0.20 \mathrm{~mm}$. For each layer height, 5 samples were made with different print speeds. For a layer height of $0.10 \mathrm{~mm}$, all samples are of acceptable quality except for the sample made at a speed of $125 \mathrm{~mm} / \mathrm{s}$, as small holes appeared on that sample. For samples made with a layer height of $0.15 \mathrm{~mm}$, the hole problem occurred with samples made at speeds of $100 \mathrm{~mm} / \mathrm{s}$ and $125 \mathrm{~mm} / \mathrm{s}$, this also happened for samples made with a layer height of $0.20 \mathrm{~mm}$. The results of the deviations are shown in Figure 3. It can be concluded that the smallest dimensional deviations at the height of the layer are $0.10 \mathrm{~mm}$, and it can be observed that the deviations are much larger at smaller printing speeds. It can also be concluded that the optimum print speed ranges from $50 \mathrm{~mm}$ s to $100 \mathrm{~mm} / \mathrm{s}$.

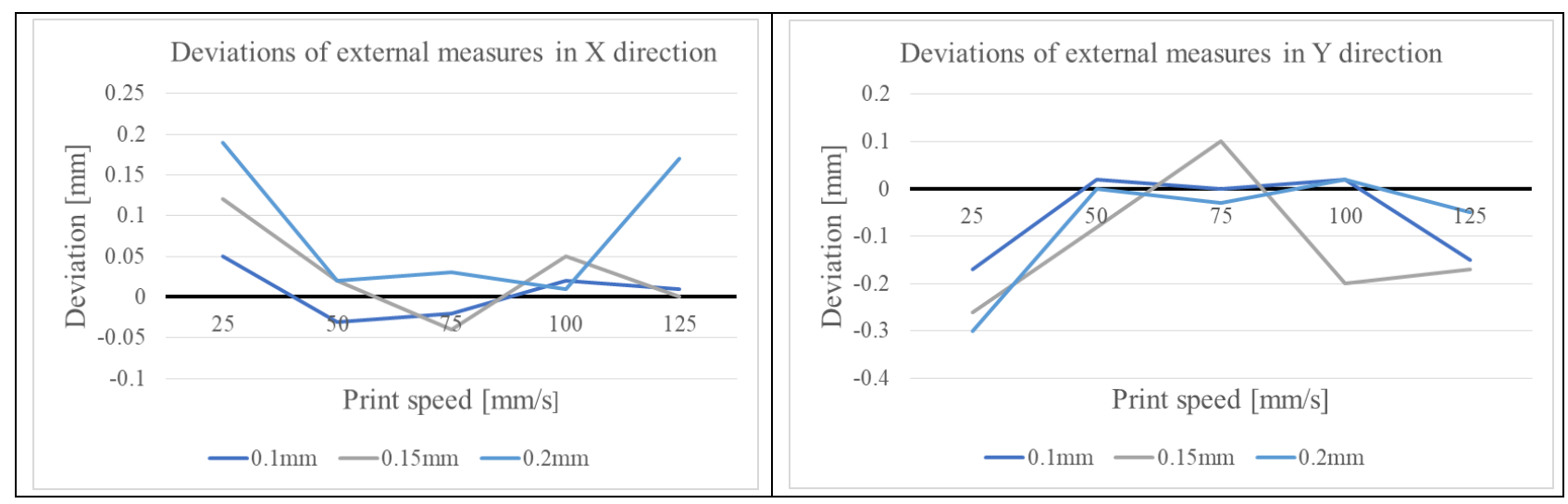

Fig. 3. Deviations of external measures in $\mathrm{X}$ and $\mathrm{Y}$ direction 
The internal dimensions of the square on the sample were also measured, and their deviation is shown in Figure 4. Although for the thickness of the layer $0.15 \mathrm{~mm}$ at speeds from $50 \mathrm{~mm} / \mathrm{s}$ to $75 \mathrm{~mm} / \mathrm{s}$, there was no deviation for the values of the internal dimensions in in the $\mathrm{Y}$ direction, there are larger deviations in the $\mathrm{X}$ direction in this interval, so it can be concluded that the layer height of $0.1 \mathrm{~mm}$ is better.

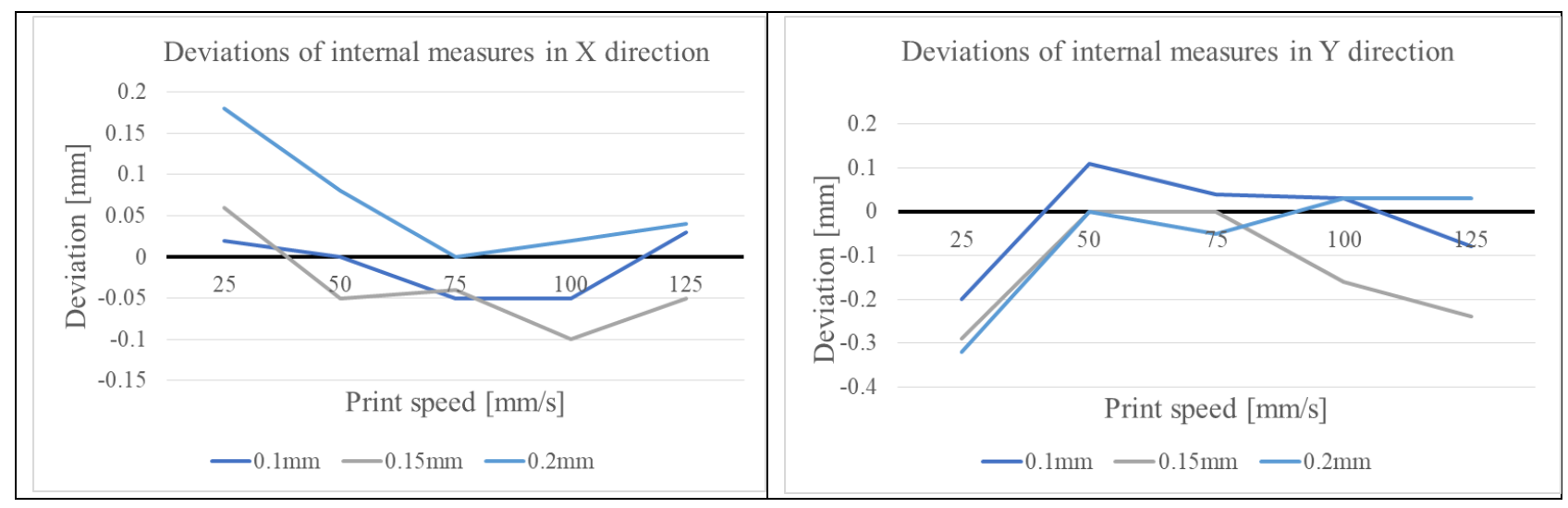

Fig. 4. Deviations of internal measures in $\mathrm{X}$ and $\mathrm{Y}$ directions

Additionally, the inner and outer diameter of the circle was measured on the samples that were printed. The results of deviations are shown in Figure 5. The first thing to see from the attached diagram is that all deviations are negative, ie. the dimensions are smaller from the defined CAD model and the deviations are significantly larger than the deviations of rectangular shapes. The diagram below shows that the maximum deviations are greater for the inside diameters than for the outer ones. Taking into account the results of measuring the outer and inner measurements of the square and the circle, it was concluded that the optimum temperature is $210^{\circ} \mathrm{C}$ when making the product with PLA material. The optimum print speed on the Ultimaker 2+ ranges from $50 \mathrm{~mm} / \mathrm{s}$ to $100 \mathrm{~mm} / \mathrm{s}$, while the optimum layer height is $0.10 \mathrm{~mm}$. With these parameters, a product made with FDM technology will have the smallest dimension deviations from the defined CAD model.

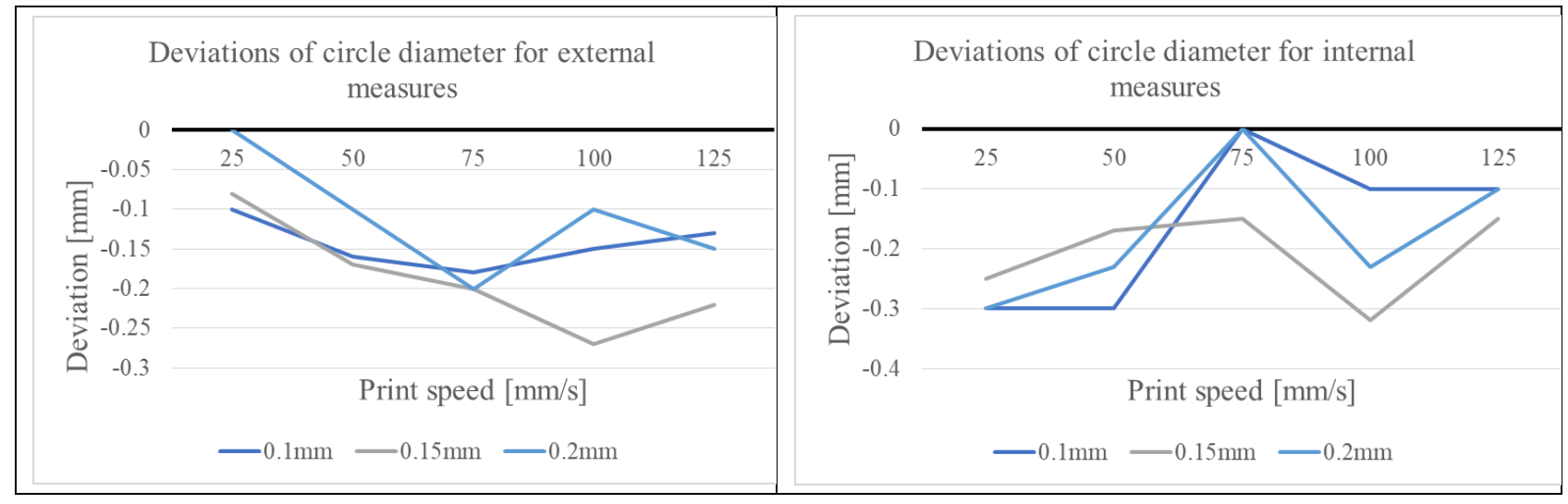

Fig. 5. Deviations of circle diameter from the dimensions defined by the 3D CAD model

\subsection{Effect of materials and technology on dimensional deviations}

For the purpose of comparing the deviations of product dimensions made with the previously defined optimal parameters of SLA and FDM procedure, 4 samples were made. The two samples produced by SLA technology are made of different material, to show whether the material has any effect on dimensional accuracy. Samples made with FDM technology are of the same material, but PVA support structure was used to create one sample. The external and internal dimensions in the $\mathrm{X}$ and $\mathrm{Y}$ directions are compared. The appearance of the samples is shown in Figure 6 and Figure 7 shows the deviations of the dimensions of the samples made by SLA and FDM. It can be concluded that the smallest deviations are obtained on the sample made on the Form 2 device and the material is a transparent resin, where the maximum deviation is $0.05 \mathrm{~mm}$. The largest deviations were obtained on the sample made on the Ultimaker 3 when a water-soluble PVA support structure was used. Based on the obtained diagram, it was concluded that products made with SLA technology have smaller dimensional deviations, which means that SLA technology is in principle more accurate than FDM. 

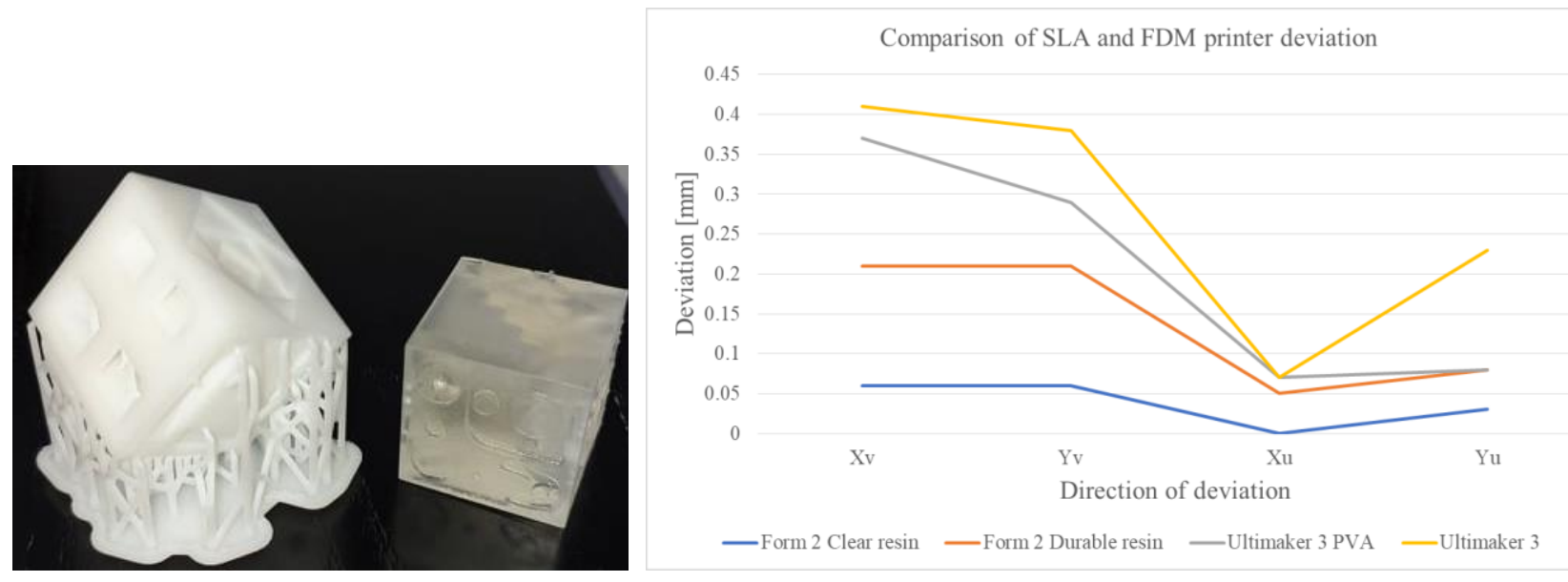

Fig. 6. The appearance of a sample made with SLA technology with and without

Fig. 7. Comparison of the deviations of the sample dimensions made support structure

\subsection{Effect of device type on dimensional deviation}

To test the effect of the type of device on the deviation of product dimensions relative to the CAD model, four identical samples, on four different devices, were made; Ultimaker 2+, Ultimaker 3 and Ultimaker S5 for FDM technology and Formlabs Form 2 for SLA technology. There are more circles on the made samples, so their dimensional deviation was determined, because larger deviations occur when making the circles. The sample appearance and print parameters are shown in Figure 8, and the results of dimensional deviations are shown graphically in Figure 9. It can be seen that the smallest dimensional deviations were obtained on a sample made using SLA technology, on the Formlabs Form 2. This sample obtained smaller values than those on the CAD model. Other devices have also received negative deviations, except for the Ultimaker 3, which has the largest deviations. The new Ultimaker S5 device gives the smallest dimensional deviation from other FDM devices, thus justifying the title of the best desktop device with two extruders for 2019.

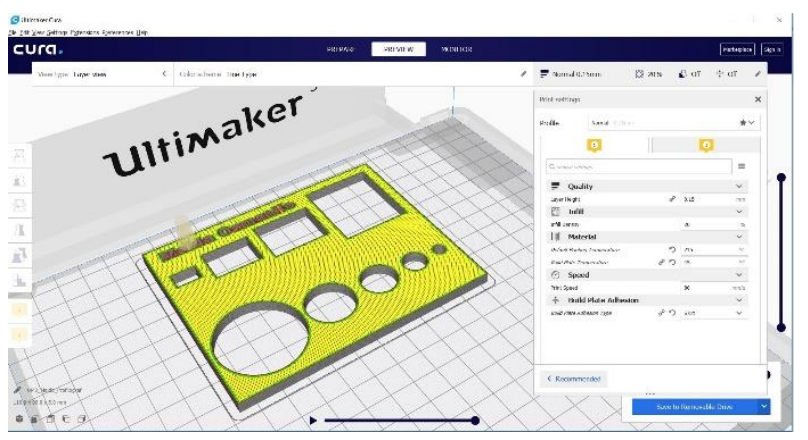

Fig. 8. Sample appearance and print parameters

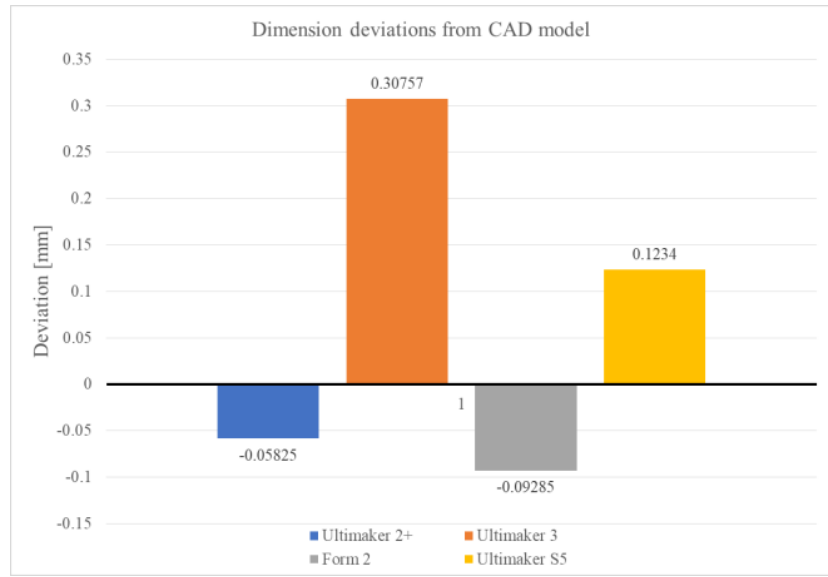

Fig. 9. Dimension deviation from CAD model on different devices

\subsection{Surface roughness testing on samples produced by FDM and SLA technology}

To test the surface roughness, samples were made on the above devices for SLA and FDM technology. Two of the three samples obtained on the SLA are made of transparent resin with varying layer height, and it has been proven that the layer height significantly affects the roughness value, figure 10. The third sample obtained by SLA technology is made of stiff resin, which gives smooth surfaces (visual control). Thus, the effect of the type of resin on surface roughness was examined. The difference between these two layer heights is mostly reflected in the printing time, which is twice as long by 0.1 compared to $0.05 \mathrm{~mm}$. When choosing a layer height, it is necessary to make a decision about the importance of surface roughness for that product, and whether it is possible to save printing time by increasing the layer height.

The results of testing the surface roughness on samples made by FDM and SLA technologies on different devices, one without the use of support material and the other with the PVA support material, are shown in Figure 11. 
Based on the diagram shown, it was concluded that the samples made SLA technology has lower surface roughness than samples made with FDM technology. Although when the sample is made using FDM technology with a very small layer height, such as $0.06 \mathrm{~mm}$, then the surface roughness is approximately equal to the surface roughness of the samples made with SLA technology. However, if the height of the sample layer made by FDM technology is the same as that of SLA technology, then the surface roughness is much higher.

The reason for the large deviation in roughness when applying PVA is reflected in the small holes on the model that remain due to cracking of PVA material during melting. SLA technology always produces smooth surfaces, even at higher layer heights.

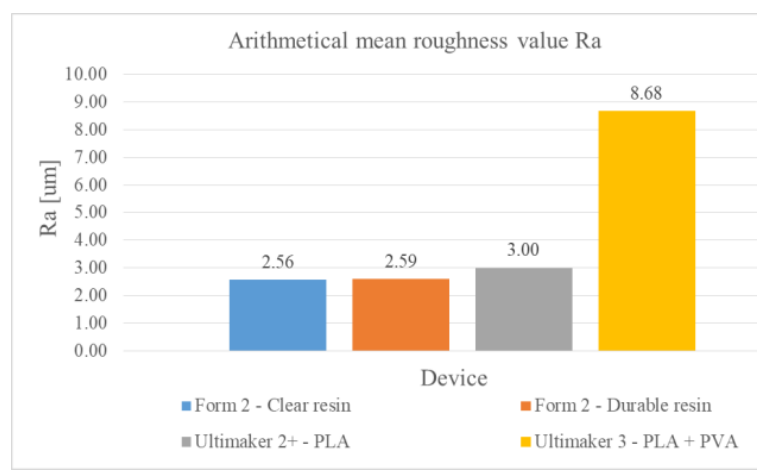

Fig. 10. Arithmetical mean roughness value for two different layer heights - SLA technology

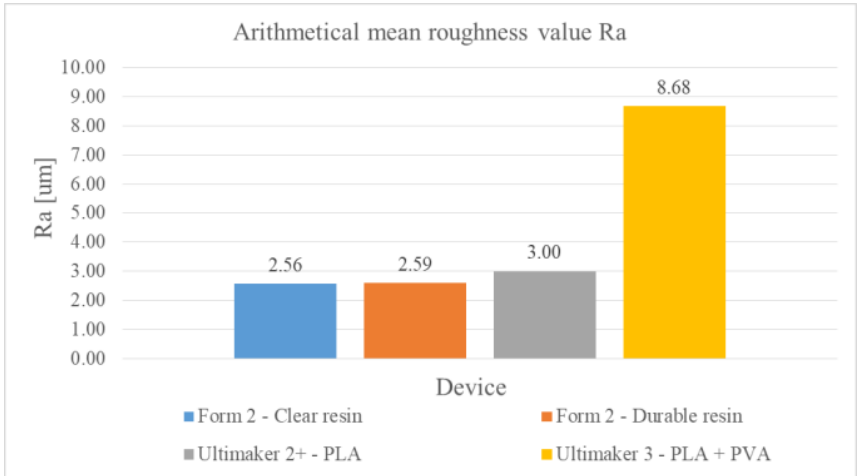

Fig. 11. Arithmetical mean roughness value of samples printed by SLA and FDM technologies on different devices

\section{Conclusion}

In order to take advantage of SLA and FDM additive technologies and to achieve better product quality, it is necessary to optimize all process parameters. By analyzing the results of the experiments performed in this paper, it can be concluded that there is a relationship between the process parameters and the quality of the finished product. By varying the various process parameters, optimal parameters were obtained in order to produce a smooth surface product and minimize dimensional deviations relative to the CAD model.

Testing of products printed on FDM devices has shown that the print speed parameter, which directly affects the manufacturing time, does not significantly affect the dimensional accuracy, while the temperature parameter which does not affect the manufacturing time, has a great influence on the dimensional accuracy of the product. The experiment found that the optimum temperature when working with PLA material on FDM devices ranges from $210{ }^{\circ} \mathrm{C}$ to $220{ }^{\circ} \mathrm{C}$.

It was concluded that the layer height parameter had the greatest influence on the appearance and dimension deviations of the product. It is a parameter that affects production time and product quality, and also has a significant effect on the surface roughness of the finished product. Experimental studies have shown that the smaller the thickness of the layer, the lower the surface roughness. The assumption that the roughness of SLA technology is significantly better than that of FDM technology is valid in the case where use PVA support material which causes irregularities. When printing with only one material, with a very small layer height, it has been proven that the difference in roughness is almost insignificant.

The authors of this paper plan to analyze and explore other additive technologies. Using reverse engineering and available additive process devices, they plan to test new materials with optimization of process parameters as well as product design for various uses.

\section{References}

[1] Isksioui, H.; El Gharad, A.; Oubrek, M. (2018). Experimental optimization of fused deposition modeling process parameters: a Taguchi process approach for dimension and tolerance control, Proceedings of the International Conference on Industrial Engineering and Operations Management, Paris, France.

[2] Ala aldin, A.; Ala Quttawi; Buraaq, A.; Arturo, G. (2017). Experimental Optimization of Fused Deposition Modelling Processing Parameters: a Design-for-Manufacturing Approach. 45th SME North American Manufacturing Research Conference, NAMRC 45, LA, USA.

[3] Parmar, B. D.; Parmar, N. G. (2015). Optimization of Fused Deposition Modeling (FDM) Process parameters for improving dimensional accuracy using Grey Taguchi Method, International Journal of Advance Engineering and Research Development, Volume 2,Issue 3.

[4] Padhi, S.; Das, H.; Sahu, R. K.; Sood, A. K. (2017). Optimization of fused deposition modeling process parameters using a fuzzy inference system coupled with Taguchi philosophy, Advances in Manufacturing, SSN 2095-3127, Volume 5, Number 3. 
[5] Čekić, A.; Begić-Hajdarević Đ.; Muhamedagić, K.; Guzanović, N. (2018). Experimental Investigations of Process Parameters Influence on Dimensional Accuracy and Mechanical Properties of FDM Manufactured Parts, Proceedings of the 29th DAAAM International Symposium, pp.0210-0214, B. Katalinic (Ed.), Published by DAAAM International, ISBN 978-3-902734-20-4, ISSN 1726-9679, Vienna, Austria.

[6] Choudhari, C. M.; Patil, V. D. (2016). Product Development and its Comparative Analysis by SLA, SLS and FDM Rapid Prototyping Processes. IOP Conf. Series: Materials Science and Engineering 149 (2016) 012009 doi:10.1088/1757-899X/149/1/012009.

[7] Polak, R.; Sedlacek, F.; Raz, K. (2018). Determination of FDM printer settings with regard to geometrical accuracy, Proceedings of the 28th DAAAM International Symposium,pp.0561-0566, B. Katalinic (Ed.), Published by DAAAM International, ISBN 978-3-902734-11-2, ISSN 1726-9679, Vienna, Austria.

[8] Velerga, A. P.; Batista, M.; Fernandez-Vidal, S. R.; Gomez-Parra, A.; Marcos, M. (2016). Preliminary study of the influence of manufacturing parameters in Fused Deposition Modeling, Proceedings of the 26th DAAAM International Symposium, pp.1004-1008, B. Katalinic (Ed.), Published by DAAAM International, ISBN 978-3902734-07-5, ISSN 1726-9679, Vienna, Austria. 